EVIDENCE BASED PUBLIC HEALTH POLICY AND PRACTICE

\title{
To control and beyond: moving towards eliminating the global tuberculosis threat
}

Timothy F Brewer, S Jody Heymann

J Epidemiol Community Health 2004;58:822-825. doi: 10.1136/jech.2003.008664

For 10 years the World Health Organisation has had a single answer to the deadly threat of tuberculosis (TB)provide treatment to smear positive patients and watch them take it. In contrast with confident statements about how global TB would be brought under control when directly observed therapy, short course (DOTS) was introduced, TB continues to rise worldwide. The introduction of selected multiple drug resistant TB treatment programmes, "DOTS-Plus", although important, also focuses on therapy for active TB. HIV endemic countries in particular have experienced tremendous increases in TB despite having DOTS programmes. A critical review of recent epidemiological data and computer models shows that the present international strategy of concentrating on providing treatment for smear positive TB, DOTS and DOTS-Plus, is likely to have only a modest impact on population based TB control. Effective global TB control will require strategies that go beyond relying on treatment of people with active disease.

See end of article for authors' affiliations

Correspondence to:

Correspondence to:
Dr T Brewer, Department of Medicine, Mount Auburn Hospital, 330 Mount Auburn Street, Cambridge, MA 02138, USA; tbrewer@mah.

harvard.edu

Accepted for publication 26 January 2004 regions is unable to contain $\mathrm{TB}$ at all. ${ }^{8}$ Control is defined here as the progressive decline in the incidence and prevalence of a disease in a population ultimately leading to its elimination. After almost 10 years of a control strategy that has done little to reduce or to eliminate TB, global TB control needs to be reassessed.

\section{IS TREATMENT SUFFICIENT TO CONTROL TB?}

DOTS refers to both an approach for treating active $\mathrm{TB}$ and a strategy for reducing the prevalence of TB in populations. Although the origins of DOTS have been debated, ${ }^{9}$ case finding and treatment of active TB form the theoretical rationale for the use of DOTS as a strategy to reduce $\mathrm{TB}$ prevalence in populations. Using Netherlands data from the 1950s to 1970s, Karel Styblo concluded that TB control programmes must be based on the diagnosis and treatment of active TB cases and that chemoprophylaxis (also known as preventive therapy or treatment of latent TB infection), had essentially no role in population based TB control. ${ }^{10}$ The Netherlands data Styblo used to reach these conclusions were based on "intensive" active population based case finding and treatment of all bacillary cases. ${ }^{10}$ DOTS, in contrast, relies on passive case finding with the goal of detecting $70 \%$ of smear positive cases and curing $85 \%$ of those detected. ${ }^{11}$ The problem of relying on DOTS is underscored by the numbers. DOTS proponents assume that effective treatment for $60 \%$ $(0.7 \times 0.85)$ of smear positive cases will produce progressive declines in global TB. ${ }^{12}$ Moreover, only $44 \%$ of all TB cases are smear positive. ${ }^{13}$ The premise that $\mathrm{TB}$ can be eliminated by treating $26 \%$ of all TB cases $(0.60 \times 0.44)$ has not been demonstrated.

TB epidemiology today differs substantially in many regions from that studied by Dr Styblo to reach his conclusions concerning the primacy of case finding and treatment over prophylaxis. Dr Styblo concluded that chemoprophylaxis had "very little, if any, impact on the time of eradication of tuberculosis in the population because the present risk of tuberculosis is very low..."10 In many HIV endemic countries, this assumption is no longer true. Among HIV infected persons with latent $\mathrm{TB}$ infection, the risk of active disease is as much as $3 \%-10 \%$ per year $^{14}{ }^{15}$; in one group of South African gold miners, the annual rate of active TB is $2.5 / 100 .^{16}$

Abbreviations: TB, tuberculosis; DOTS, directly observed therapy, short course 


\section{Value of improving TB treatment programmes}

Fewer than $25 \%$ of $\mathrm{TB}$ patients are thought to receive effective treatment. ${ }^{6}$ About $50 \%$ of untreated TB patients eventually die from their disease. Effective treatment reduces TB mortality rates to under $5 \%,{ }^{17}$ shortens morbidity, decreases transmission to others, and reduces the prevalence of drug resistant disease. ${ }^{18}$ For these reasons, effective TB treatment programmes need to be expanded so they are available to all TB patients.

With ineffective treatment programmes, TB, particularly drug resistant TB, can increase. In the 1980s, New York City TB programmes failed to adequately follow up and cure patients with active $\mathrm{TB}^{19}$ These programme failures contributed to a multiple drug resistant TB (MDR-TB) epidemic characterised by extensive nosocomial transmission that cost hundreds of lives and in excess of one billion US dollars to be contained. $^{2021}$ MDR-TB is a global problem, ${ }^{22}$ and data demonstrate that standard DOTS treatment programmes are inadequate for the treatment of multiple drug resistant disease. ${ }^{23}$ The failure of DOTS treatment programmes to adequately cure MDR-TB has lead to the creation of "DOTSPlus," or DOTS plus therapy with second line agents for MDR-TB in selected situations. ${ }^{24}$

Given the lack of a highly efficacious vaccine to protect susceptible people from TB infection, effective treatment programmes are an essential component of current global TB control efforts. DOTS and DOTS-Plus treatment programmes that improve patient outcomes should be expanded. However, that does not mean that the present international focus on expanding effective treatment programmes to the exclusion of other approaches such as preventive therapy, the existing DOTS and DOTS-Plus strategies, is optimal or sufficient for reducing the global burden of TB.

\section{Limitations of treatment as a TB control strategy}

TB may seem unusual among infectious diseases because of characteristics like its long latency period. Yet, while infectious diseases vary in their epidemiology, pathogenesis, and availability of treatments, concepts gleaned from past eradication programmes are applicable to TB elimination efforts. ${ }^{25}$ Control is a prelude to elimination. ${ }^{2}$ Successful control programmes to date have relied on protecting susceptible people from acquiring disease regardless of whether effective treatments $\mathrm{did}^{26}$ or did not exist. ${ }^{25}$ The present global strategy for TB control, in contrast, is based on preventing people with active TB from transmitting disease. The lack of historical precedents for this approach is worrisome for the successful control and ultimate elimination of TB with this strategy.

There are additional reasons to be concerned that DOTS is inadequate as a TB control strategy. Firstly, even in well run DOTS programmes, TB transmission can still occur in a high proportion of cases by the time the index case is identified. ${ }^{27}$ The initial symptoms of TB are non-specific; even when a sputum smear is ordered, the sensitivity of this test for detecting active TB is only $55 \%-74 \%{ }^{28}{ }^{29}$ Patient delays in seeking care and healthcare worker delays in recognising and starting treatment for $\mathrm{TB}$ also contribute to transmission. ${ }^{30}$

A second limitation of DOTS is the inadequate attention to smear negative cases. Although smear positive patients are more infectious, smear negative patients can and do transmit TB infection to others. ${ }^{31}$ An estimated $56 \%$ of all prevalent TB cases, or 9.1 million people worldwide, have smear negative TB. ${ }^{13}$ Assuming the transmission data from San Francisco are representative of smear negative TB patients globally, smear negative people may be responsible for about 1.4 million new TB cases annually. An estimated 2 billion people have latent TB infection. ${ }^{13}$ They are and will continue to be an important source of new TB cases, yet DOTS does not prevent these cases from occurring.

The most convincing evidence of the failure of DOTS as a strategy to reduce the global burden of TB comes from subSaharan Africa. In the face of the spreading HIV pandemic, DOTS programmes have seen substantial increases in the number of TB cases despite maintaining reasonable treatment completion rates. ${ }^{8} 32$

\section{Needs of millions unmet}

Despite widespread evidence that DOTS is failing to contain TB in sub-Saharan Africa, ${ }^{32}$ WHO officials recommend expanding DOTS to control TB in this region. ${ }^{33}$ Yet there are no current epidemiological studies to support this DOTS only or DOTS first approach. Moreover, under a fully implemented DOTS programme by 2010 , WHO models estimate that there would still be about 160 million TB cases and 50 million deaths over a 23 year period. ${ }^{12}$ Imagine the outcry if WHO said that after fully implementing the global polio vaccination programme, there would still be 160 million cases of polio over the next 20 years. A TB control programme in which $75 \%$ of $\mathrm{TB}$ cases and deaths still occur is clearly an inadequate goal.

\section{PREVENTION NEEDS TO ACCOMPANY TREATMENT}

Epidemiological evidence accumulated over decades supports the use of combined prevention and treatment strategies for TB control. In one of the most successful population based control efforts undertaken, TB treatment and community wide isoniazid prophylaxis led to a $50 \%$ decrease in the rate of new infections over a six year period among Eskimos in Bethel, Alaska. ${ }^{10}{ }^{34}$ The rise and subsequent control of TB in New York City is another example. Although New York's success has been attributed by some primarily to DOTS, ${ }^{35}$ improvements in infection control practices in hospitals, homeless shelters and correctional facilities, changes in treatment regimens, improvements in diagnostic methods, and expanded use of preventive therapy also were used to reverse this TB epidemic. ${ }^{21}$

Computer simulation models of population based TB control show that combinations of treatment and prevention approaches are more effective than strategies based on treatment alone. ${ }^{36}$

Models also show that the combined use of treatment for latent and active TB is more effective at reducing TB in HIV

\section{Key points}

- Although directly observed therapy, short course (DOTS), the World Health Organisation's global control policy, has been in place for 10 years, the global burden of tuberculosis (TB) continues to rise with millions of cases and deaths each year.

- Recent epidemiological and modelling studies suggest that combinations of prevention and treatment strategies are likely to be more effective than DOTS for controlling TB.

- Improving TB control worldwide requires approaches that go far beyond the current WHO programme of treating smear positive TB patients.

- A combined approach of expanded chemoprophylaxis for HIV negative and positive people, population based prevention strategies for drug sensitive TB and MDR$T B$, and treatment accompanied by improved surveillance is needed. 
infected populations than current strategies, $^{37}$ and widespread treatment of latent TB infection in HIV infected persons in Africa has been recommended. ${ }^{38}$ How treatment of latent infection might best be used for TB control in HIV endemic areas is unknown. Limited projects have been undertaken. ${ }^{39}$ What is needed however, are studies of sufficient size and scope to re-examine the role of preventive therapy in population based TB control, particularly in HIV endemic settings. These types of studies have been undertaken to examine the impact of sexually transmitted disease treatment for HIV prevention ${ }^{40}$; similar designs should be used to examine the impact of population based treatment of TB infection on TB control.

\section{APPROACHES NEED TO FIT LOCAL EPIDEMIOLOGY}

There is no evidence to indicate that one TB control strategy is universally applicable, and mounting evidence that it is not. Yet there remains only one global TB control strategy-DOTS. In Peru, with low rates of HIV, DOTS has resulted in high cure rates and modest declines in TB incidence. ${ }^{7}$ In Botswana, where almost $40 \%$ of the adult population are HIV infected, ${ }^{41}$ there has been a pronounced increase in TB despite maintaining high treatment compliance rates with DOTS. ${ }^{8}$ In parts of Russia where MDR-TB is prevalent, DOTS has had low cure rates and no demonstrable impact on incidence. ${ }^{42}$ Instead of a single global strategy, control programmes must be developed that consider key epidemiological characteristics such as TB, HIV, and MDR prevalence as well as available resources.

\section{BETTER SURVEILLANCE IS NECESSARY TO ASSESS SUCCESSES AND FAILURES}

WHO collects TB case notifications and treatment outcomes to assess global control efforts. ${ }^{4}$ Treatment outcome data are essential for assessing treatment programme performance, but they do not necessarily show whether TB is successfully being eliminated in a population. A number of sub-Saharan African TB programmes have rising caseloads despite maintaining consistent treatment outcomes. ${ }^{8}$ For many TB high burden countries, there are no good data on the incidence or prevalence of TB cases or deaths. Years after instituting of one of the best DOTS programmes in the world, officials were uncertain whether TB was being controlled in Peru. ${ }^{73}$ Some at WHO have proposed complex models to assess DOTS or argued that the absence of control groups makes it hard to evaluate the impact of DOTS. ${ }^{43}$ However, when good surveillance data exist, demonstrating the introduction of effective control interventions is straightforward. ${ }^{21} 26$ Surveillance data need to be gathered so that the effectiveness of TB control and elimination strategies can be assessed.

\section{RESEARCH TO FILL TOOL GAPS}

More effective vaccines, rapid inexpensive tests to better diagnose latent $\mathrm{TB}$ infection and smear negative $\mathrm{TB}$, and shorter, safer, inexpensive treatments for active and latent TB are needed. ${ }^{44}$ Advances in any one of these areas would be important, and research in all these areas must be actively pursued. Field studies to optimise the use of existing tools in different epidemiological settings also need to be undertaken. One of the important lessons from the smallpox eradication programme is the value of ongoing research to improve control efforts. ${ }^{25}$

\section{CONCLUSIONS}

Despite almost 10 years of DOTS, much of the world remains no closer to achieving control of TB. In sub-Saharan Africa and parts of Eastern Europe, TB has increased over the past decade. In response to this lack of progress, WHO and others have called for further expansion of DOTS. Even where DOTS programmes have led to declines in TB incidence, the benefits have been modest.

The time has come to re-evaluate TB control strategies. There are those who may argue that we understand how best to control $\mathrm{TB}$, and the primary problem is implementation. ${ }^{33}$ This simplistic answer fails to recognise both past experience from other successful infectious disease control efforts ${ }^{25}$ and the reality that, in some parts of the world, TB continues to rise despite well run DOTS treatment programmes. ${ }^{8} 38$

The failure of DOTS as a TB control strategy does not mean this approach is without benefits. DOTS programmes that improve treatment outcomes and prevent the emergence of drug resistance should be developed further. However, controlling TB will require much more than treating people diagnosed with smear positive disease. To substantially reduce TB worldwide, we will have to do much more than connect the DOTS.

\section{Authors' affiliations}

T F Brewer, Department of Medicine, Mount Auburn Hospital, Brigham and Women's Hospital and Harvard Medical School, USA

S J Heymann, Department of Society, Human Development and Health, Harvard School of Public Health, USA

Funding: this work was supported by a Clinical Investigator Award no 1 K08 Al01444-01A1 from the National Institute of Allergy and Infectious Diseases.

Conflicts of interest: none declared.

\section{REFERENCES}

1 Raviglione MC, Snider DE Jr, Kochi A. Global epidemiology of tuberculosis. Morbidity and mortality of a worldwide epidemic. JAMA 1995;273:220-6.

2 Enarson DA. Controlling tuberculosis - is it really feasible? Tuber Lung Dis 2000;80:57-9

3 Raviglione MC, Pio A. Evolution of WHO policies for tuberculosis control, 1948-2001. Lancet 2002;359:775-80.

4 World Health Organisation WH. Global tuberculosis control. WHO Report 2001. Geneva: World Health Organisation; 2001 2001. WHO/CDS/TB/ 2001.287.

5 Reichman LB. Tuberculosis elimination-what's to stop us? Int J Tuberc Lung Dis 1997; 1:3-11.

6 Blanc L, Floyd K, Norval PY, et al. Global DOTS expansion plan. Progress in TB control in high-burden countries, 2001. Geneva: World Health Organisation; 2001. WHO/CDS/TB/2001.11.

7 Suarez PG, Watt CJ, Alarcon E, et al. The dynamics of tuberculosis in response to 10 years of intensive control effort in Peru. J Infect Dis 2001;184:473-8.

8 Kenyon TA, Mwasekaga MJ, Huebner R, et al. Low levels of drug resistance amidst rapidly increasing tuberculosis and human immunodeficiency virus coepidemics in Botswana. Int J Tuberc Lung Dis 1999;3:4-11

9 Mitchison DA. The origins of DOT. Int J Tuberc Lung Dis 1998;2:863-5.

10 Styblo K. Epidemiology of tuberculosis. Vol 24. The Hague: Royal Netherlands Tuberculosis Association, 1991.

11 Maher D, Chaulet P, Spinaci S, et al. Treatment of tuberculosis: guidelines for national programmes. Vol WHO/TB/97.220. 2nd ed. Geneva: World Health Organisation, 1997.

12 Dye C, Garnett GP, Sleeman K, et al. Prospects for worldwide tuberculosis control under the WHO DOTS strategy. Directly observed short-course therapy. Lancet 1998;352:1886-91.

13 Dye C, Scheele S, Dolin P, et al. Consensus statement. Global burden of tuberculosis: estimated incidence, prevalence, and mortality by country. WHO Global Surveillance and Monitoring Project. JAMA 1999;282:677-86.

14 Whalen CC, Johnson JL, Okwera A, et al. A trial of three regimens to prevent tuberculosis in Ugandan adults infected with the human immunodeficiency virus. Uganda-Case Western Reserve University Research Collaboration. N Engl J Med 1997;337:801-8.

15 Selwyn PA, Sckell BM, Alcabes P, et al. High risk of active tuberculosis in HIVinfected drug users with cutaneous anergy. JAMA 1992;268:504-9.

16 Churchyard GJ, Kleinschmidt I, Corbett EL, et al. Mycobacterial disease in South African gold miners in the era of HIV infection. Int J Tuberc Lung Dis 1999;3:791-8.

17 Cohn DL, Catlin BJ, Peterson KL, et al. A 62-dose, 6-month therapy for pulmonary and extrapulmonary tuberculosis. A twice-weekly, directly observed, and cost-effective regimen. Ann Intern Med 1990;1 12:407-15.

18 Kim SJ, Bai GH, Hong YP. Drug-resistant tuberculosis in Korea, 1994. Int J Tuberc Lung Dis 1997; 1:302-8.

19 Brudney K, Dobkin J. A tale of two cities: tuberculosis control in Nicaragua and New York City. Semin Respir Infect 1991;6:261-72.

20 Frieden TR, Sherman LF, Maw KL, et al. A multi-institutional outbreak of highly drug-resistant tuberculosis: epidemiology and clinical outcomes. JAMA 1996;276:1229-35. 
21 Frieden TR, Fujiwara PI, Washko RM, et al. Tuberculosis in New York Cityturning the tide. N Engl J Med 1995;333:229-33.

22 Espinal MA, Laszlo A, Simonsen L, et al. Global trends in resistance to antituberculosis drugs. World Health Organization-International Union against Tuberculosis and Lung Disease Working Group on Anti-Tuberculosis Drug Resistance Surveillance. N Engl J Med 2001;344:1294-303.

23 Espinal MA, Kim SJ, Suarez PG, et al. Standard short-course chemotherapy for drug-resistant tuberculosis: treatment outcomes in 6 countries. JAMA 2000;283:2537-45

24 Gupta R, Raviglione MC, Espinal MA. Should tuberculosis programmes invest in second-line treatments for multidrug-resistant tuberculosis (MDR-TB)? Int J Tuberc Lung Dis 2001;5:1078-9.

25 Henderson DA. The challenge of eradication: lessons from past eradication campaigns. Int J Tuberc Lung Dis 1998;2(suppl 1):S4-8.

26 Wenger JD. Epidemiology of Haemophilus influenzae type $b$ disease and impact of Haemophilus influenzae type $b$ conjugate vaccines in the United States and Canada. Pediatr Infect Dis J 1998;17(suppl):S132-6.

27 Bishai WR, Graham NM, Harrington S, et al. Molecular and geographic patterns of tuberculosis transmission after 15 years of directly observed therapy. JAMA 1998;280:1679-84.

28 Isaac-Renton JL, Puselia BB, Allen EA, et al. Microscopic evaluation of sputum specimens submitted for Mycobacterium tuberculosis culture. Am J Clin Pathol 1985;84:361-3.

$29 \mathrm{Kim}$ TC, Blackman RS, Heatwole KM, et al. Acid-fast bacilli in sputum smears of patients with pulmonary tuberculosis. Prevalence and significance of negative smears pretreatment and positive smears post-treatment. Am Rev Respir Dis 1984;129:264-8

30 Allos BM, Genshelmer KF, Bloch AB, et al. Management of an outbreak of tuberculosis in a small community. Ann Intern Med 1996:125:114-17.

31 Behr MA, Warren SA, Salamon H, et al. Transmission of Mycobacterium tuberculosis from patients smear-negative for acid-fast bacilli. Lancet 1999;353:444-9
32 Cantwell MF, Binkin NJ. Tuberculosis in sub-Saharan Africa: a regional assessment of the impact of the human immunodeficiency virus and National Tuberculosis Control Program quality. Tuber Lung Dis 1996;77:220-5.

33 Bleed D, Dye C, Raviglione MC. Dynamics and control of the global tuberculosis epidemic. Curr Opin Pulm Med 2000:6:174-9.

34 Comstock GW, Ferebee SH, Hammes LM. A controlled trial of communitywide isoniazid prophylaxis in Alaska. Am Rev Respir Dis 1967;95:935-43.

35 World Health Organisation. WHO report on the TB epidemic: stop TB at the source. Vol WHO/TB/95.184. Geneva: WHO, 1995.

36 Brewer TF, Heymann SJ, Colditz GA, et al. Evaluation of tuberculosis control policies using computer simulation. JAMA 1996;276:1898-903.

37 Heymann SJ. Modelling the efficacy of prophylactic and curative therapies for preventing the spread of tuberculosis in Africa. Trans $R$ Soc Trop Med Hyg 1993:87:406-11.

38 De Cock KM, Chaisson RE. Will DOTS do it? A reappraisal of tuberculosis control in countries with high rates of HIV infection. Int J Tuberc Lung Dis 1999;3:457-65.

39 Stop-TB. TB and HIV: the ProTEST initiative. http://archives.healthdev.net/ stop-tb/msg00069.html (accessed 5 Jun 2002).

40 Grosskurth H, Mosha F, Todd J, et al. Impact of improved treatment of sexually transmitted diseases on HIV infection in rural Tanzania: randomised controlled trial. Lancet 1995;346:530-6.

41 Masupu K, Jimbo W, Chipfakacha V, et al. Botswana 2000 HIV seroprevalence sentinel survey amongst pregnant women and men with sexually transmitted diseases. Gaborone: National AIDS Coordinating Agency, December 2000.

42 Kimerling ME. The Russian equation: an evolving paradigm in tuberculosis control. Int J Tuberc Lung Dis 2000;4(suppl 2):S160-7.

43 Dye C. Tuberculosis 2000-2010: control, but not elimination. Int J Tuberc Lung Dis 2000;4(suppl 2):S146-52

44 Miller B, Castro KG. Sharpen available tools for tuberculosis control, but new tools needed for elimination. JAMA 1996;276:1916-17.

\section{THE JECH GALLERY}

\section{Laboratory in a rural hospital. Guinea Bissau (Africa) 2000}

nequalities between developed and developing countries are a serious problem in the field of health research. The Human Development Report 2003 emphasises that $90 \%$ of global researching for pharmaceutical drugs goes to diseases that account for $10 \%$ of the disease burden in developing countries. Tropical diseases, incidence of HIV/ AIDS, and the lack of diffusion existing technologies affect particularly poor countries. Financing of health research and the social use of technology may be two of the main ways to improve global health.

Diana Gil

Universidad de Alicante, Ap-99 Alicante, Spain E-03080; diana.gil@ua.es

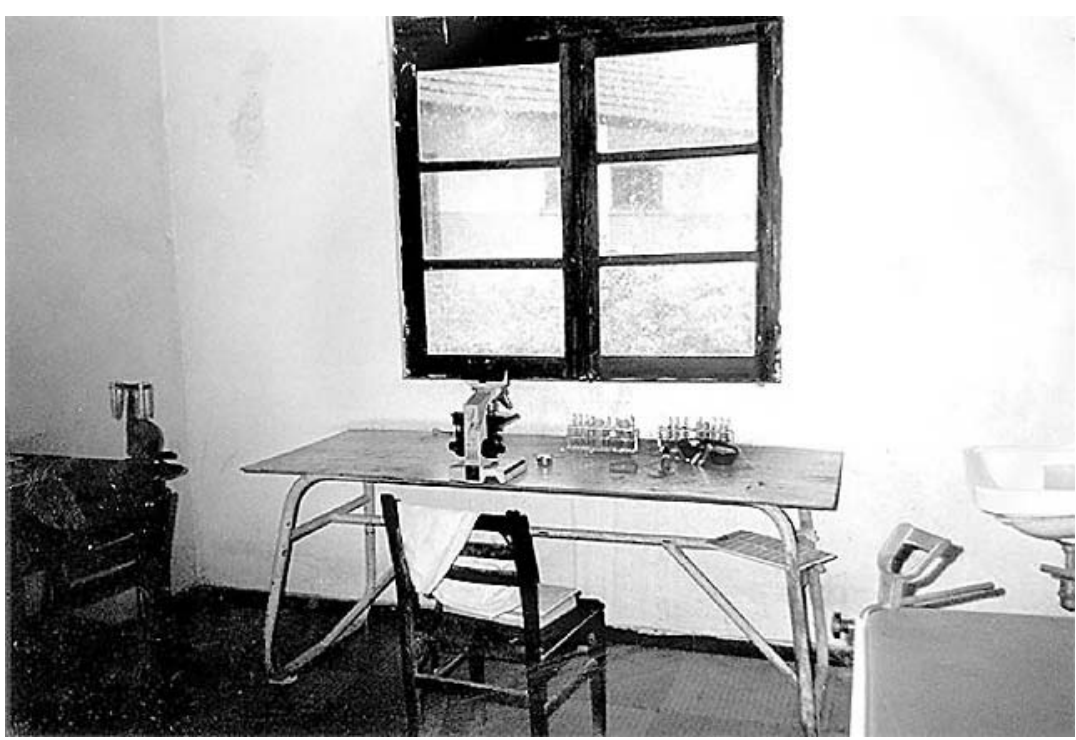

